\title{
What do pedometer counts represent? A comparison between pedometer data and data from four different questionnaires
}

\author{
Katrien A De Cocker*, Ilse M De Bourdeaudhuij and Greet M Cardon \\ Department of Movement and Sports Sciences, Ghent University, Watersportlaan 2, B-9000 Ghent, Belgium
}

Submitted 12 June 2007: Accepted 14 January 2008: First published online 20 March 2008

\begin{abstract}
Objectives: To compare physical activity (PA) reported through pedometer registrations (step counts) with $\mathrm{PA}$ reported in four different questionnaires; to compare step count thresholds (7500, 10000 and 12500 steps/d) with the PA guideline of $30 \mathrm{~min}$ of moderate to vigorous PA (MVPA) per day.

Subjects: A sample of 310 healthy adults, mean age 38.7 (SD 11.9) years, volunteered to participate. Forty-seven per cent was male and $93 \%$ of the sample was employed.

Methods: PA was assessed by interview (Minnesota Leisure Time Physical Activity Questionnaire (MLTPAQ)), three self-administered questionnaires (long version and short version of the International Physical Activity Questionnaire (long-form IPAQ, short-form IPAQ), Baecke questionnaire) and seven consecutive days of pedometer registration.

Results: Step counts correlated positively with questionnaire-based PA. The strongest correlations were found between step counts and total PA reported in the long-form IPAQ $\left(r_{\mathrm{s}}=0 \cdot 37\right)$, moderate PA reported in the short-form IPAQ $\left(r_{\mathrm{s}}=0 \cdot 33\right)$, total and moderate PA reported in the MLTPAQ $\left(r_{\mathrm{s}}=0 \cdot 32\right)$, and the total and leisure-time PA indices (excluding sport) reported in the Baecke questionnaire $\left(r_{\mathrm{s}}=0 \cdot 44\right)$. According to step counts, $22.6 \%$ of the participants were somewhat active, $18 \cdot 7 \%$ active and $39 \cdot 4 \%$ highly active. As assessed by the long-form IPAQ, short-form IPAQ and MLTPAQ, the guideline of $30 \mathrm{~min} \mathrm{MVPA} / \mathrm{d}$ was reached by respectively $85 \cdot 4 \%, 84 \cdot 8 \%$ and $68 \cdot 0 \%$ of participants.

Conclusion: Pedometer-based data offer adequate information to discriminate between levels of PA. Caution is needed when comparing active samples based on different PA recommendations.
\end{abstract}

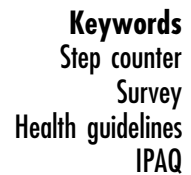

The amount of usual physical activity (PA) accumulated by an individual is strongly related with all-cause morbidity and mortality risk $^{(1)}$. Healthy adults should accumulate $30 \mathrm{~min}$ or more of moderate-intensity aerobic PA on $5 \mathrm{~d}$ each week or a minimum of $20 \mathrm{~min}$ of vigorousintensity aerobic activity on $3 \mathrm{~d}$ each week $^{(2)}$. The use of step count recommendations as useful behavioural PA targets has been suggested in the past ${ }^{(3,4)}$. These step count thresholds are more practical than the $30 \mathrm{~min}$ MVPA/d guideline since they do not imply constant time tracking and summing of at least moderate-intensity activity during the day, which is impractical for PA assessment on individual and population levels. Additionally, more detailed pedometer-based indices for public health (sedentary: $<5000$ steps/d; low active: 5000-7499 steps/d; somewhat active: 7500-9999 steps/d; active: 10000-12 499 steps/d; highly active: $\geq 12500$ steps/d) have been introduced by Tudor-Locke and Bassett $^{(5)}$.
Being able to accurately quantify the amount of PA accrued during daily life is necessary for researchers and health professionals to better understand PA behaviour and to develop successful programmes to increase activity levels in various populations. Traditionally, PA has been measured through questionnaires, the strengths and limitations of which are well known ${ }^{(6)}$. Recognized benefits are the possibility to assess different dimensions of PA, the ability to collect data from a large number of people at low cost, and the unobtrusiveness of the instrument ${ }^{(7)}$. However, there are limitations in subjects' recall ability and social desirability bias can cause overreporting of $\mathrm{PA}^{(7)}$. Recently, more attention has been given to objective instruments to assess PA, e.g. accelerometers and pedometers. Pedometers have been shown to provide a valid and accurate measure of ambulatory activities in free-living conditions ${ }^{(8,9)}$. They are simple to use, more objective than surveys, and less expensive (approximately \$US 20-50) compared with 
accelerometers (approximately \$US 150-500). Despite their limitations such as variability between different brands, insensitivity to non-ambulatory activities (i.e. cycling, swimming) and increased errors at slow walking speeds $(<60 \mathrm{~m} / \mathrm{min})^{(8)}$, pedometers have become popular devices for public use and for researchers. Moreover, step counts have proved to be useful in PA studies in freeliving populations ${ }^{(8)}$. However, the question remains of which exactly dimensions of PA are measured by pedometers. Several researchers ${ }^{(8,10)}$ report that pedometer step counts are an appropriate measurement of the distance walked, while others believe that pedometers also enable the quantification of ambulatory behaviour during occupational, leisure-time, household and transportation activity $^{(11,12)}$. In addition, one could wonder if step counts are simply a measure for walking or if they can also be associated with self-reports of PA that encompass intensity (other moderate and vigorous PA, besides walking). Therefore, the first purpose of the present study was to compare pedometer data with data from questionnaires, the most commonly used ${ }^{(7)}$ and practical method for PA assessment in large-scale studies ${ }^{(13)}$. The objective was to evaluate the associations between step counts and PA (walking, moderate PA, vigorous PA) reported in four different validated questionnaires: the intervieweradministered Minnesota Leisure Time Physical Activity Questionnaire $^{(14)}$ (MLTPAQ), the self-administered long version and self-administered short version of the International Physical Activity Questionnaire ${ }^{(15)}$ (long-form IPAQ, short-form IPAQ), and the self-administered Baecke Questionnaire $^{(16)}$. Additionally, questionnaire-based PA was compared between the five 'step count groups' based on the pedometer health indices of Tudor-Locke and Bassett ${ }^{(5)}$.

A third objective of the present study was to compare step count thresholds (7500, 10000 and 12500 steps/d) with the guideline of $30 \mathrm{~min}$ of moderate to vigorous PA (MVPA) per day. Wilde et $a l^{(17)}$ found that sedentary women who added a $30 \mathrm{~min}$ walk to their daily habits accumulated approximately 10000 steps. Another study ${ }^{(18)}$ also revealed that on days when women took a $30 \mathrm{~min}$ walk, their average step count was close to 10000 . Other researchers $^{(19)}$ found that women who took 10000 steps/d were more likely to meet the current MVPA guideline, compared with those not accumulating as many steps.
Miller and Brown ${ }^{(20)}$ found only a moderate level of agreement between meeting $10000 \mathrm{steps} / \mathrm{d}$ and $150 \mathrm{~min}$ or more of PA over five or more sessions per week. However, no research could be located in either gender or in a European sample assessing whether step count thresholds are corresponding to the $30 \mathrm{~min} \mathrm{MVPA} / \mathrm{d}$ guideline. Therefore, the present study explored whether adults reaching 7500, 10000 and 12500 steps/d also reached $30 \mathrm{~min}$ MVPA/d, based on self-reports.

\section{Methods}

\section{Participants and procedures}

A convenience sample of 310 volunteers (146 men) living in Flanders, Belgium participated in the present study. Participant characteristics are shown in Table 1. No gender differences were found for the proportions of employed participants, mean ages and average daily step counts.

All participants were visited at home by research assistants for the completion of the MLTPAQ. After this interview, participants were asked to complete the self-administered long-form IPAQ, the self-administered short-form IPAQ and the Baecke questionnaire. Then, participants were asked to register pedometer-based step counts for seven consecutive days. They were instructed to wear the pedometer on their waistband or belt during waking hours. All participants were asked to carry on their usual activities, to remove the pedometer only while swimming, bathing or showering, and to complete an activity log at the end of each day. All participants provided written informed consent and the study was approved by the Ethical Committee of Ghent University. Research assistants (masters-level graduates, native speakers) were given $2 \mathrm{~h}$ of training and interview practice.

\section{Instruments}

\section{Pedometers}

The Yamax Digiwalker SW-200 (Yamax, Tokyo, Japan) was used in the present study as it is known to be a valid, reliable and accurate instrument for counting steps in adult populations ${ }^{(21)}$.

Table 1 Characteristics of the study participants: healthy adult volunteers, Flanders, Belgium

\begin{tabular}{|c|c|c|c|c|c|c|c|}
\hline & \multicolumn{2}{|c|}{ Total group } & \multicolumn{2}{|c|}{ Male } & \multicolumn{2}{|c|}{ Female } & \multirow[b]{2}{*}{ Gender comparison } \\
\hline & $n$ & $\%$ & $n$ & $\%$ & $n$ & $\%$ & \\
\hline \multirow{3}{*}{$\begin{array}{l}\text { Gender } \\
\text { Employed }\end{array}$} & 310 & $100 \cdot 0$ & 146 & $47 \cdot 1$ & 164 & $52 \cdot 9$ & $\chi^{2}=1 \cdot 05^{\mathrm{NS}}$ \\
\hline & 288 & $92 \cdot 9$ & 139 & $95 \cdot 2$ & 149 & $90 \cdot 9$ & $\chi^{2}=0.35^{\mathrm{NS}}$ \\
\hline & Mean & SD & Mean & SD & Mean & SD & \\
\hline Age (years) & $38 \cdot 7$ & $11 \cdot 9$ & $39 \cdot 1$ & $12 \cdot 5$ & $38 \cdot 3$ & $11 \cdot 4$ & $t=0.56^{\mathrm{NS}}$ \\
\hline Daily step counts & 12087 & 4888 & 12452 & 4983 & 11762 & 4792 & $t=1 \cdot 24^{\mathrm{NS}}$ \\
\hline
\end{tabular}

NS, $P>0.05$. 


\section{Activity log}

Based on procedures of Tudor-Locke et $a l^{(22)}$, participants were asked to keep daily activity records in an activity log during the seven consecutive days of pedometer registration. They were requested to record the date, the number of steps recorded at the end of the day, and the type and duration of non-ambulatory activities (e.g. $20 \mathrm{~min}$ of biking/swimming). Following established guidelines $^{(23,24)}, 150$ steps were added to the daily total for every minute of reported biking and/or swimming. The average daily step count was 9981 (SD 3455) without adding the equivalent for biking/swimming and 12087 (SD 4888) with the added steps for biking/swimming. Of the total sample, 152 people $(49 \cdot 0 \%)$ reported biking/ swimming during the week of pedometer registration (mean: $7 \cdot 6(\mathrm{SD} 15 \cdot 1) \mathrm{min} / \mathrm{d})$.

\section{MLTPAQ}

A structured interview was used to solicit detailed information on leisure-time PA over a 1-year period. A Dutch version of the validated MLTPAQ, developed for the Belgian Physical Fitness Study, was used ${ }^{(6,14,25)}$. Participants' engagement in different activities was queried, together with the number of months per year, the monthly frequency and the duration of the activity. Activities were classified as walking (structured walking for transport or in leisure time), moderate-intensity PA (MPA) or vigorous-intensity PA (VPA), based on their energy requirements (MPA: 3-6 MET; VPA: $>6 \mathrm{MET} ; \mathrm{MET}=$ metabolic energy equivalent task $)^{(26)}$.

\section{Long-form IPAQ}

The self-administered long-form IPAQ was used to assess PA at work, transport-related PA, domestic and gardening activities, and PA during leisure time in a usual week. Total times engaged in walking, MPA and VPA, all expressed in min/week, were computed according to the guidelines (www.ipaq.ki.se). The IPAQ has been shown to be a valid and reliable instrument for measuring PA in Europe $^{(15)}$ and in Flanders, Belgium ${ }^{(27)}$.

\section{Short-form IPAQ}

PA was assessed using the self-administered short-form IPAQ, which provides information on the time spent walking, in MPA and in VPA (min/week) in a usual week. This version of the IPAQ has been found to be valid and reliable ${ }^{(15)}$.

\section{Baecke questionnaire}

In the Baecke questionnaire ${ }^{(16)}$, responses were scored on a five-point scale and resulted in three different indices reflecting PA during work (work index), PA during leisure time excluding sport (LT index) and PA during sport activities (sport index). The summation of the three indices was defined as the overall PA index (total PA index). Good validity of the Baecke questionnaire for the assessment of PA was found in the past ${ }^{(28,29)}$.

\section{Data analysis}

Analyses were carried out using the SPSS for Windows statistical software package version $12 \cdot 0$ (SPSS Inc., Chicago, IL, USA). Average daily steps were calculated and values above 20000 steps/d were recorded as 20000 steps/d to limit unrealistically high average step counts $^{(30)}$. Because of the non-normal distributions in PA data, Spearman correlation coefficients $\left(r_{\mathrm{s}}\right)$ were calculated to assess the relationship between step counts and questionnaire-based PA. The same technique was used to assess the correlations between PA data derived from the different questionnaires. Correlations were interpreted as low $(<0 \cdot 30)$, moderate $(0 \cdot 30-0 \cdot 50)$ or high $(>0 \cdot 50)$. Differences in questionnaire-based PA between the five step count groups based on the pedometer indices ${ }^{(5)}$ were evaluated with multivariate ANOVA. First, the skewed questionnaire outcomes were log-transformed to approximate normal distributions. Parametric analyses were performed on the log-transformed data and adjusted for age, gender and employment status. $F$ values, $P$ values and partial $\eta^{2}$, as a measure of the effect size, are reported. For reasons of clarity and comparability, the means and standard deviations of the non-transformed data are used in Table 3. Finally, cross-tabulations of the number of participants (not) reaching the step count thresholds of 7500, 10000 and 12500 steps/d and/or the guideline of $30 \mathrm{~min} \mathrm{MVPA} / \mathrm{d}$ were performed, and the percentages of agreement between the different PA recommendations were calculated based on the cross-tabulations. A $P$ value $\leq 0.05$ was considered as statistically significant.

\section{Results}

The correlations between step counts and questionnairebased PA are shown in Table 2. Step counts correlated moderately with total PA $\left(r_{\mathrm{s}}=0 \cdot 37\right)$ and MPA $\left(r_{\mathrm{s}}=0.31\right)$, and lowly with walking $\left(r_{\mathrm{s}}=0 \cdot 19\right)$ and VPA $\left(r_{\mathrm{s}}=0 \cdot 25\right)$, reported in the long-form IPAQ. Low correlations were found between step counts and total PA $\left(r_{\mathrm{s}}=0 \cdot 28\right)$, walking $\left(r_{\mathrm{s}}=0 \cdot 15\right)$ and VPA $\left(r_{\mathrm{S}}=0 \cdot 20\right)$ reported in the short-form IPAQ, except for MPA $\left(r_{\mathrm{s}}=0 \cdot 33\right)$. A low correlation was found between step counts and walking $\left(r_{\mathrm{s}}=0 \cdot 10\right)$ and VPA $\left(r_{\mathrm{s}}=0 \cdot 16\right)$ reported in the MLTPAQ; total PA $\left(r_{\mathrm{s}}=0.32\right)$ and MPA $\left(r_{\mathrm{s}}=0.32\right)$ reported in the MLTPAQ correlated moderately with step counts. Finally, step counts correlated moderately with the total PA index $\left(r_{\mathrm{s}}=0 \cdot 44\right)$, LT index $\left(r_{\mathrm{s}}=0 \cdot 44\right)$ and sport index $\left(r_{\mathrm{s}}=0 \cdot 31\right)$ of the Baecke questionnaire, except for the work index $\left(r_{\mathrm{s}}=0 \cdot 19\right)$. Correlations between PA reported in the different questionnaires are also presented in Table 2.

Table 3 shows the mean (SD) amounts of questionnairebased PA (min/week) for the different step count groups divided according to the pedometer indices of TudorLocke and Bassett ${ }^{(5)}$. Significant differences between the 
five step count groups were found for total PA, MPA and VPA reported in the long-form IPAQ, short-form IPAQ and MLTPAQ. For walking, only data based on the shortform IPAQ differed significantly between the step count groups. The work, leisure-time, sport and total PA indices of the Baecke questionnaire differed significantly between the five step count groups.

In total, $80 \cdot 6 \%$ of participants reached $7500 \mathrm{steps} / \mathrm{d}$, $45.0 \%$ reached 10000 steps/d and $39 \cdot 4 \%$ reached 12500 steps/d, whereas $30 \mathrm{~min} \mathrm{MVPA} / \mathrm{d}$ was reached by $85.4 \%$ according to the long-form IPAQ, $84 \cdot 8 \%$ according to the short-form IPAQ and $68 \cdot 1 \%$ according to the MLTPAQ (Fig. 1).

Using the long-form IPAQ, the step count thresholds of 7500, 10000 and 12500 steps/d and the $30 \mathrm{~min} \mathrm{MVPA} / \mathrm{d}$ recommendation were in agreement in respectively $77 \cdot 7 \%$, $54.4 \%$ and $48.7 \%$ of the participants (see Table 4). Based on the short-form IPAQ, respectively $76 \cdot 5 \%, 51 \cdot 8 \%$ and $48 \cdot 1 \%$ of participants were well placed. Using the MLTPAQ, the recommendations were in agreement in respectively $71 \cdot 9 \%, 53 \cdot 1 \%$ and $51 \cdot 9 \%$ of the participants. Some $89 \cdot 2 \%$ of the participants reaching 7500 steps $/ \mathrm{d}, 94 \cdot 2 \%$ of those reaching 10000 steps/d and $93.4 \%$ of those reaching 12500 steps/d reached $30 \mathrm{~min} \mathrm{MVPA} / \mathrm{d}$, according to the longform IPAQ. With the short-form IPAQ these figures were respectively $88.0 \%, 90 \cdot 6 \%$ and $91 \cdot 8 \%$. Of the participants, $74.8 \%$ reaching 7500 steps $/ \mathrm{d}, 73.4 \%$ reaching 10000 steps/d and $75.4 \%$ reaching $12500 \mathrm{steps} / \mathrm{d}$ reached $30 \mathrm{~min}$ $\mathrm{MVPA} / \mathrm{d}$ based on the MLTPAQ.

\section{Discussion}

The first aim of the present study was to evaluate the associations between step counts and questionnairebased PA. Objectively measured step counts correlated positively with the subjectively reported PA levels. Significant, positive associations between step counts and questionnaire-based PA were also found in previous studies $^{(9,31)}$ conducted in the USA, where walking is one of the most commonly reported forms of $\mathrm{PA}^{(32)}$. A median correlation of $r=0.33$ (range: $0.02-0.94$ ) was found between step counts and self-reported PA in a review of mostly non-European studies ${ }^{(33)}$. Surprisingly, in the present study, a low correlation was found between step counts and walking reported in the long-form IPAQ, short-form IPAQ and MLTPAQ. An explanation for this remarkable finding could be the lack of sensitivity of questionnaires ${ }^{(34)}$ to detect walking, resulting in underreporting of walking behaviour. Bassett et al. ${ }^{(35)}$ also found that subjects underestimated their daily walking distance in the College Alumnus Questionnaire, compared with pedometer-based values. Furthermore, different types of walking were assessed through the various questionnaires. The long-form IPAQ asked about the combination of walking in various domains (i.e. work, transport, 
Table 3 Differences in questionnaire-based physical activity (PA) across step count groups: healthy adult volunteers, Flanders, Belgium

\begin{tabular}{|c|c|c|c|c|c|c|c|c|c|c|c|c|c|}
\hline \multirow{4}{*}{$\begin{array}{l}\text { Step count range } \\
\text { Participants }\end{array}$} & \multicolumn{10}{|c|}{ Pedometer index } & \multirow[b]{4}{*}{$F(P)$} & \multirow{4}{*}{$\begin{array}{l}\text { Post hoc } \\
\text { analysest }\end{array}$} & \multirow[b]{4}{*}{$\eta^{2}$} \\
\hline & \multirow{2}{*}{\multicolumn{2}{|c|}{$\begin{array}{c}\text { Sedentary } \\
<5000 \\
n 12\end{array}$}} & \multirow{2}{*}{\multicolumn{2}{|c|}{$\begin{array}{c}\text { Low active } \\
\begin{array}{c}5000-7499 \\
n 55\end{array}\end{array}$}} & \multirow{2}{*}{\multicolumn{2}{|c|}{$\begin{array}{c}\text { Somewhat active } \\
\begin{array}{c}7500-9999 \\
n 84\end{array}\end{array}$}} & \multirow{2}{*}{\multicolumn{2}{|c|}{ 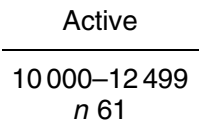 }} & \multirow{2}{*}{\multicolumn{2}{|c|}{$\begin{array}{c}\text { Highly active } \\
\geq 12500 \\
n 64\end{array}$}} & & & \\
\hline & & & & & & & & & & & & & \\
\hline & Mean & SD & Mean & SD & Mean & SD & Mean & SD & Mean & SD & & & \\
\hline \multicolumn{14}{|l|}{ Total PA (min/week) } \\
\hline Long-form IPAQ & 462 & 405 & 722 & 676 & 1069 & 820 & 1329 & 804 & 1542 & 904 & $12 \cdot 4^{\star \star \star}$ & $\mathrm{a}, \mathrm{h}$ & 0.14 \\
\hline Short-form IPAQ & 243 & 268 & 838 & 927 & 772 & 733 & 1286 & 1080 & 1458 & 1113 & $7 \cdot 4^{\star \star \star}$ & $\mathrm{c}, \mathrm{h}$ & 0.09 \\
\hline MLTPAQ & 199 & 194 & 347 & 309 & 416 & 279 & 524 & 430 & 485 & 326 & $8 \cdot 2^{\star \star \star}$ & $c, e, f, g, h$ & $0 \cdot 10$ \\
\hline \multicolumn{14}{|l|}{ Walking (min/week) } \\
\hline Long-form IPAQ & 81 & 52 & 247 & 361 & 317 & 392 & 450 & 459 & 432 & 485 & $1 \cdot 8^{\mathrm{NS}}$ & & 0.02 \\
\hline Short-form IPAQ & 58 & 63 & 558 & 702 & 424 & 538 & 754 & 753 & 634 & 702 & $5 \cdot 4^{\star \star *}$ & $c, e, g, h$ & 0.07 \\
\hline MLTPAQ & 103 & 116 & 76 & 73 & 106 & 116 & 110 & 131 & 108 & 121 & $1 \cdot 2^{\mathrm{NS}}$ & & 0.02 \\
\hline \multicolumn{14}{|l|}{ MPA (min/week) } \\
\hline Long-form IPAQ & 303 & 331 & 334 & 371 & 525 & 441 & 611 & 434 & 733 & 476 & $7 \cdot 8^{\star \star \star}$ & $a, b, c, h$ & $0 \cdot 10$ \\
\hline Short-form IPAQ & 82 & 116 & 147 & 294 & 210 & 290 & 349 & 539 & 545 & 620 & $6 \cdot 8^{\star \star \star}$ & $a, b, c, d, h$ & 0.08 \\
\hline MLTPAQ & 104 & 107 & 255 & 298 & 292 & 238 & 373 & 371 & 336 & 253 & $7 \cdot 4^{\star \star \star}$ & $c, f, g, h$ & 0.05 \\
\hline \multicolumn{14}{|l|}{ VPA (min/week) } \\
\hline Long-form IPAQ & 55 & 178 & 129 & 194 & 155 & 258 & 215 & 302 & 263 & 352 & $4 \cdot 6^{\star \star \star}$ & $c, d, f, h$ & 0.06 \\
\hline Short-form IPAQ & 47 & 144 & 113 & 188 & 135 & 243 & 172 & 272 & 206 & 257 & $2 \cdot 7^{*}$ & $a, c, d, f, h$ & 0.04 \\
\hline MLTPAQ & 3 & 10 & 17 & 31 & 27 & 67 & 37 & 65 & 46 & 80 & $4 \cdot 2^{\star \star}$ & $a, c, d, h$ & 0.05 \\
\hline \multicolumn{14}{|l|}{ Baecke questionnaire } \\
\hline Work index & $1 \cdot 8$ & 0.5 & $1 \cdot 8$ & $0 \cdot 6$ & $2 \cdot 0$ & 0.6 & $2 \cdot 2$ & $0 \cdot 7$ & $2 \cdot 3$ & $0 \cdot 6$ & $6 \cdot 9^{\star \star \star}$ & $a, b, f, h$ & 0.09 \\
\hline LT index & $1 \cdot 9$ & $0 \cdot 6$ & $2 \cdot 3$ & 0.5 & $2 \cdot 5$ & 0.6 & $2 \cdot 6$ & 0.6 & $2 \cdot 6$ & 0.7 & $6 \cdot 3^{\star \star \star}$ & $f, g, h$ & 0.09 \\
\hline Sport index & $1 \cdot 4$ & $1 \cdot 2$ & $1 \cdot 9$ & $1 \cdot 3$ & $1 \cdot 9$ & $1 \cdot 2$ & $2 \cdot 2$ & $1 \cdot 2$ & $2 \cdot 5$ & $2 \cdot 1$ & $3 \cdot 2^{*}$ & $a, b, c, d, f, h$ & 0.05 \\
\hline Total PA index & $5 \cdot 1$ & $1 \cdot 9$ & $6 \cdot 0$ & $1 \cdot 5$ & $6 \cdot 4$ & $1 \cdot 4$ & $7 \cdot 0$ & 1.5 & $7 \cdot 4$ & 1.5 & $10 \cdot 4^{\star \star *}$ & $\mathrm{a}, \mathrm{c}, \mathrm{h}$ & $0 \cdot 13$ \\
\hline
\end{tabular}

IPAQ, International Physical Activity Questionnaire (long-form, long version of the questionnaire; short-form, short version of the questionnaire); MLTPAQ, Minnesota Leisure Time Physical Activity Questionnaire; MPA, moderate physical activity; VPA, vigorous physical activity.

Significance of differences between the five groups: ${ }^{\star} P \leq 0.05,{ }^{\star \star} P \leq 0.01,{ }^{\star \star \star} P \leq 0.001$ (NS, $P>0.05$ ).

tSome post hoc pairwise comparisons were not significantly different: a, sedentary-low active NS; b, sedentary-somewhat active NS; c, low activesomewhat active NS; d, low active-active NS; e, low active-highly active NS; f, somewhat active-active NS; g, somewhat active-highly active NS; h, active-highly active NS.

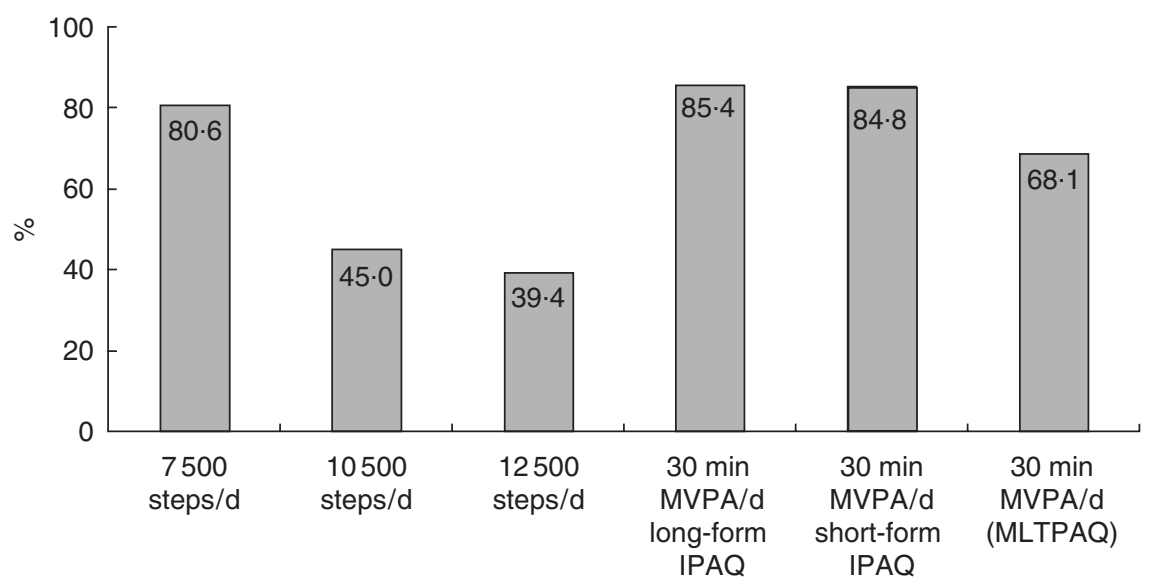

Fig. 1 Percentage of participants reaching the step count of 7500 steps/d, 10000 steps/d and 12500 steps/d, and the standard of $30 \mathrm{~min}$ of moderate to vigorous physical activity (MVPA) per day, as assessed by three different questionnaires: the long version and short version of the International Physical Activity Questionnaire (long-form IPAQ, short-form IPAQ) and the Minnesota Leisure Time Physical Activity Questionnaire (MLTPAQ)

home, leisure time) while the MLTPAQ assessed leisure/ pleasure walking and walking to work only. The pedometer measured all ambulatory activity throughout the day.

Furthermore, differences in questionnaire-based PA between groups based on the pedometer indices of Tudor-Locke and Bassett ${ }^{(5)}$ were evaluated. Results showed that the classification of activity levels based on step counts also highlighted differences in self-reported levels of PA (low to medium effect sizes). The more active participants were, based on step counts, the higher the levels of total, MPA and VPA reported in the long-form IPAQ, short-form IPAQ and MLTPAQ. The application of 
Table 4 Number of participants reaching both, one or neither of two types of physical activity recommendations: $7500 \mathrm{steps} / \mathrm{d}$, $10000 \mathrm{steps} / \mathrm{d}, 12500 \mathrm{steps} / \mathrm{d}$ and the $30 \mathrm{~min}$ of moderate to vigorous physical activity (MVPA) per day standard, as assessed by three different questionnaires

\begin{tabular}{|c|c|c|}
\hline \multirow[b]{2}{*}{$30 \mathrm{~min}$ MVPA/d based on... } & \multicolumn{2}{|c|}{7500 steps } \\
\hline & Not reached & Reached \\
\hline \multicolumn{3}{|l|}{ Long-form IPAQ } \\
\hline Not reached & 18 & 27 \\
\hline Reached & 42 & 223 \\
\hline \multicolumn{3}{|l|}{ Short-form IPAQ } \\
\hline Not reached & 17 & 30 \\
\hline Reached & 43 & 220 \\
\hline \multicolumn{3}{|l|}{ MLTPAQ } \\
\hline Not reached & 36 & 63 \\
\hline \multirow[t]{3}{*}{ Reached } & 24 & 187 \\
\hline & \multicolumn{2}{|c|}{10000 steps } \\
\hline & Not reached & Reached \\
\hline \multicolumn{3}{|l|}{ Long-form IPAQ } \\
\hline Not reached & 37 & 8 \\
\hline Reached & 133 & 131 \\
\hline \multicolumn{3}{|l|}{ Short-form IPAQ } \\
\hline Not reached & 34 & 13 \\
\hline Reached & 136 & 126 \\
\hline \multicolumn{3}{|l|}{ MLTPAQ } \\
\hline Not reached & 62 & 37 \\
\hline \multirow[t]{2}{*}{ Reached } & 108 & 102 \\
\hline & \multicolumn{2}{|c|}{12500 steps } \\
\hline
\end{tabular}

\begin{tabular}{lrr} 
& & \\
\cline { 2 - 3 } Long-form IPAQ & 37 & 8 \\
$\quad$ Not reached & 151 & 114 \\
$\quad$ Reached & & \\
Short-form IPAQ & 37 & 10 \\
$\quad$ Not reached & 151 & 112 \\
$\quad$ Reached & & \\
MLTPAQ & 69 & 30 \\
$\quad$ Not reached & 119 & 92 \\
Reached & \\
\hline
\end{tabular}

IPAQ, International Physical Activity Questionnaire (long-form, long version of the questionnaire; short-form, short version of the questionnaire); MLTPAQ, Minnesota Leisure Time Physical Activity Questionnaire.

these findings is that individuals who engaged more in MPA and VPA accumulated more steps per day. Again, unexpectedly, this was not the case for walking reported in the long-form IPAQ and MLTPAQ. Only walking in the short-form IPAQ differed significantly between step count groups. All indices (work, leisure-time, sport and total PA) based on the Baecke questionnaire also increased gradually when step counts augmented. Concluding, step counts are capable of discriminating between total, MPA and VPA reported in the different questionnaires.

A third objective of the present study was to compare currently used PA guidelines, to show differences in the percentages of participants reaching the step count thresholds. Of the participants, $80 \cdot 6 \%$ reached 7500 steps/d, $45.0 \%$ reached 10000 steps/d and 39.4\% reached $12500 \mathrm{steps} / \mathrm{d}$. The guideline of $30 \mathrm{~min} \mathrm{MVPA/d}$, on the other hand, was reached by $85.4 \%$ according to the long-form IPAQ, followed by $84.8 \%$ according to the short-form IPAQ and by $68 \cdot 1 \%$ according to the MLTPAQ. There are various possible explanations for this discrepancy. It is known that over-reporting of PA may occur when using self-reported questionnaires, including the IPAQ $^{(7)}$. The lower percentage according to the MLTPAQ could be explained by the 1-year time frame of the questionnaire, which could cause recall biases. Also the fact that the MLTPAQ was interviewer-administered may have had an influence: research assistants were trained to detect over-reporting of $\mathrm{PA}^{(6)}$.

The current study also explored whether reaching different step count thresholds was sufficient to reach $30 \mathrm{~min}$ MVPA/d. When participants reached 7500 steps/d, the MVPA recommendation was reached in $89 \cdot 2 \%$ (by longform IPAQ; $88.0 \%$ by short-form IPAQ). Of participants, $94 \cdot 2 \%$ (by long-form IPAQ; $90 \cdot 6 \%$ by short-form IPAQ) of those reaching 10000 steps/d reached $30 \mathrm{~min}$ MVPA/d. Participants reaching 12500 steps $/ \mathrm{d}$ reached $30 \mathrm{~min}$ $\mathrm{MVPA} / \mathrm{d}$ in $93.4 \%$ (by long-form IPAQ; $91 \cdot 8 \%$ by shortform IPAQ) of cases. All figures based on the MLTPAQ were lower (respectively 74.8\%, 73.4\% and 75.4\%). However, these results indicated that step count thresholds are stringent enough. Le Masurier et al. ${ }^{(19)}$ found that $91 \%$ of women reaching the 10000 steps/d standard accumulated more than $30 \mathrm{~min} \mathrm{MVPA} / \mathrm{d}$ based on accelerometer data. In the present study, it was easier for participants reaching the step count thresholds to reach $30 \mathrm{~min} \mathrm{MVPA} / \mathrm{d}$, rather than the other way around. No more than half of the participants (respectively $49 \cdot 6 \%$, $48 \cdot 1 \%$ and $48.6 \%$ based on the long-form IPAQ, shortform IPAQ and MLTPAQ) reaching $30 \mathrm{~min} \mathrm{MVPA} / \mathrm{d}$ reached 10000 steps $/ \mathrm{d}$, for example. Welk et $a l^{(9)}$ reported that participants who performed more than $30 \mathrm{~min}$ of PA daily reached at least 10000 steps/d some $73 \%$ of the time. Tudor-Locke et al. ${ }^{(36)}$ found that approximately 3000 steps are expected in $30 \mathrm{~min}$ of moderate-intensity ambulatory activity.

The present average step count level (12 100 steps/d) is clearly higher than that of a representative sample of Belgian adults (9700 steps/d) ${ }^{(23)}$. A possible explanation could be the fact that the present study population is a convenience sample of mostly working volunteers, implying cautious interpretations and limited generalizability of the results.

The present results reflect that caution is needed when assessing PA standards, especially when using different methods. It is remarkable that despite moderate correlations between step counts and questionnaire-based PA, the percentages reaching the standards differ notably. The subjective nature of questionnaires, possibly causing over-reporting, can be an explanation of the discrepancy. To avoid this problem, a gold standard, such as doubly labelled water or accelerometers, could be used to determine if the $30 \mathrm{~min} \mathrm{MVPA} / \mathrm{d}$ guideline is effectively reached. 
In summary, there is a modest relationship between step counts and questionnaire-based PA in the present European sample. Objective pedometers not only provide a measurement of walking but also give an indication of total, MPA and VPA. Even though pedometers alone cannot discriminate between the intensity of activities nor reflect the amount of time spent in specific intensity PA categories, they provide sufficient information to be valuable in PA assessment in large, free-living populations. Less agreement was found between the currently used PA guidelines (30 min MVPA/d and step count thresholds), suggesting that caution is needed when comparing active quantities in different samples based on different methods.

\section{Acknowledgements}

The authors declare that they have no competing interests. The study was not funded.

K.A.D.C. participated in the data collection, analysis and interpretation, and led the writing of the paper. G.M.C. and I.M.D.B. participated in the data collection, conceptualization of the study and provided substantive feedback on the manuscript. All authors have read and approved the final manuscript.

The authors would like to acknowledge all subjects participating in the study.

\section{References}

1. Blair SN, Cheng Y \& Holder S (2001) Is physical activity or physical fitness more important in defining health benefits? Med Sci Sports Exerc 33, S379-S399.

2. Haskell W, Lee I, Pate R, Powell K, Blair S, Franklin B, Macera C, Heath G, Thompson P \& Bauman A (2007) Physical activity and public health: updated recommendation for adults from the American College of Sports Medicine and the American Hearth Association. Med Sci Sports Exerc 39, 1423-1434.

3. Hatano Y (1993) Use of the pedometer for promoting daily walking exercise. Int Counc Health Phys Educ Recreation 29, 4-8.

4. Hatano Y (1997) Prevalence and use of pedometer. Res J Walking 1, 45-54.

5. Tudor-Locke C \& Bassett DR (2004) How many steps per day are enough? Preliminary pedometer indices for public health. Sports Med 34, 1-8.

6. Montoye HJ, Kemper HC, Saris WH \& Washburn RA (1996) Measuring Physical Activity and Energy Expenditure. Champaign, IL: Human Kinetics.

7. Sallis J \& Saelens BE (2000) Assessment of physical activity by self-report: status, limitations, and future directions. Res Q Exerc Sport 71, 1-14.

8. Bassett DR, Ainsworth BE, Legget SR, Mathien CA, Main JA, Hunter DC \& Duncan GE (1996) Accuracy of five electronic pedometers for measuring distance walked. Med Sci Sports Exerc 28, 1071-1077.

9. Welk GJ, Differding JA, Thompson RW, Blair SN, Dziura J \& Hart P (2000) The utility of the Digi-Walker step counter to assess physical activity patterns. Med Sci Sports Exerc 32, S481-S488.
10. Shephard FK (1989) Assessment of physical activity and energy needs. Am J Clin Nutr 50, 1195-1200.

11. Hornbuckle LM, Bassett DR \& Thompson DL (2005) Pedometer-determined walking and body composition variables in African-American women. Med Sci Sports Exerc 37, 1069-1074.

12. Sequeira MM, Rickenbach $M$, Wietlisbach V, Tullen B \& Schutz Y (1995) Physical activity assessment using a pedometer and its comparison with a questionnaire in a large population study. Am J Epidemiol 142, 989-999.

13. Bouchard C, Shepard RJ, Stephens T, Sutton JR \& McPherson BD (1990) Exercise, Fitness, and Health. A Consensus of Current Knowledge. Champaign, IL: Human Kinetics.

14. Taylor HL, Jacobs DR, Schucker B, Knudsen J, Leon AS \& Debacker G (1978) Questionnaire for the assessment of leisure time physical activities. J Chronic Dis 31, 741-755.

15. Craig CL, Marshall AL, Sjöström M et al. (2003) International Physical Activity Questionnaire: 12-country reliability and validity. Med Sci Sports Exerc 35, 1381-1395.

16. Baecke JA, Burema J \& Frijters JE (1982) A short questionnaire for the measurement of habitual physical activity in epidemiological studies. Am J Clin Nutr 36, 936-942.

17. Wilde BE, Sidman CL \& Corbin CB (1002) A 10,000-step count as a physical activity target for sedentary women. Res Q Exerc Sport 72, 411-414.

18. Hultquist CN, Albright C \& Thompson DL (2005) Comparison of walking recommendations in previously inactive women. Med Sci Sports Exerc 37, 676-683.

19. Le Masurier GC, Sidman CL \& Corbin CB (2003) Accumulating 10,000 steps: does this meet current physical activity guidelines? Res Q Exerc Sport 74, 389-394.

20. Miller R \& Brown W (2004) Meeting physical activity guidelines and average daily steps in a working population. J Phys Act Health 1, 217-225.

21. Crouter SE, Schneider PL, Karabulut M \& Bassett DR (2003) Validity of 10 electronic pedometers for measuring steps, distance and energy cost. Med Sci Sports Exerc 35, $1455-1460$.

22. Tudor-Locke C, Lind KA, Reis JP, Ainsworth BE \& Macera CA (2003) A preliminary evaluation of a pedometerassessed physical activity self-monitoring survey. Field Methods 15, 1-17.

23. De Cocker K, Cardon G \& De Bourdeaudhuij I (2007) Pedometer-determined physical activity and its comparison with the International Physical Activity Questionnaire in a sample of Belgian adults. Res $Q$ Exerc Sport 78, 429-437.

24. Miller R, Brown W \& Tudor-Locke C (2006) But what about swimming and cycling? How to 'count' non-ambulatory activity when using pedometers to assess physical activity? J Phys Act Health 3, 257-266.

25. De Backer G, Kornitzer M, Sobolski J, Dramaix M, Degré S, de Marneffe M \& Denolin H (1981) Physical activity and physical fitness levels of Belgian males aged 40-55 years. Cardiology 67, 110-128.

26. Ainsworth BE, Haskell WL, Whitt MC et al. (2000) Compendium of physical activities: an update of activity codes and MET intensities. Med Sci Sports Exerc 32, 498-504.

27. Vandelanotte C, De Bourdeaudhuij I, Sallis J, Philippaerts R \& Sjöström M (2005) Reliability and validity of a computerized and Dutch version of the International Physical Activity Questionnaire (IPAQ). J Phys Act Health 2, 63-75.

28. Pols MA, Buenodemesquita HB, Ocke MC, Wentick CA, Kemper HCG \& Collette HJA (1995) Validity and repeatability of a modified Baecke questionnaire on physical activity. Int J Epidemiol 24, 381-388. 
29. Philippaerts FM, Westerdorp KR \& Lefevre J (1999) Doubly labeled water validation of three physical activity questionnaires. Int J Sports Med 20, 284-289.

30. Tudor-Locke C, Ham S, Macera C, Ainsworth BE, Kirtland KA, Reis JP \& Kimsey Jr CD (2004) Descriptive epidemiology of pedometer-determined physical activity. Med Sci Sports Exerc 36, 1567-1573

31. Bassett DR, Schneider PL \& Huntington GE (2004) Physical activity in an old order Amish community. Med Sci Sports Exerc 36, 79-85.

32. Crespo CJ, Keteyian SJ, Heath GW \& Sempos CT (1996) Leisure-time physical activity among US adults. Arch Intern Med 17, 423-473.
33. Tudor-Locke C, Williams JE, Reis JR \& Pluto D (2002) Utility of pedometers for assessing physical activity: convergent validity. Sports Med 32, 795-808.

34. Ainsworth BE, Leon AS, Richardson MR, Jacobs DR \& Paffenbarger RS (1993) Accuracy of the college alumnus physical activity questionnaire. J Clin Epidemiol 46, 1403-1411.

35. Bassett DR, Cureton AL \& Ainsworth BE (2000) Measurement of daily walking distance - questionnaire versus pedometer. Med Sci Sports Exerc 32, 1018-1023.

36. Tudor-Locke C, Sisson SB, Collova T, Lee SM \& Swan PD (2005) Pedometer-determined step count guidelines for classifying walking intensity in a young ostensibly health population. Can J Appl Physiol 30, 666-676. 